\title{
Linfoma esofágico primário
}

\section{Primary esophageal lymphoma}

\author{
Manoel Ximenes, ECBC-DF'; Marcos Amorim Piauilino'; Humberto Alves Oliveira'; Jorge Pinto Vaz Neto²
}

\section{INTRODUÇÃO}

O linfoma primário do esôfago é um tipo extremamente raro de tumor, com menos de 30 casos relatados na literatura mundial. Numa série de casos de 1.467 linfomas gastrointestinais, foram observados três casos de linfoma esofágico primário, uma incidência de $0,2 \%{ }^{1}$. A maioria dos casos de linfoma esofágico correspondem a envolvimento secundário resultante da progressão a partir do estômago proximal, gânglios linfáticos mediastinais ou cervicais. Com o avanço da infecção pelo HIV, o linfoma de esôfago se tornou um item importante no diagnóstico diferencial das pessoas com sintomas atribuíveis ao trato gastrointestinal superior ${ }^{2}$.

\section{RELATO DO CASO}

Uma mulher de 54 anos apresentava disfagia ocasional para sólidos e líquidos com sete meses de duração. A história patológica pregressa era irrelevante, e o exame físico normal, assim como os exames laboratoriais. A telerradiografia de tórax mostrou desvio da traquéia e a esofagografia com bário mostrou um grande tumor na parte superior do esôfago torácico, ocluindo quase totalmente a luz do órgão, confirmado pela tomografia computadorizada de tórax (Figuras 1-A, B). Uma endoscopia foi realizada, mas a biópsia foi impossível por conta da facilidade de sangramento. Em 22 de junho de 2008, a paciente foi operada através de uma toracotomia direita, com remoção de uma massa esofágica de 11 centímetros (Figuras 1 C e D). Uma fístula esôfago-pleural desenvolveu-se no primeiro dia pós-operatório. Assim que a fístula se tornou orientada, confirmada por exame baritado, o dreno de tórax foi mantido aberto, a paciente liberada e incentivada a tomar grandes quantidades de líquidos em casa até o fechamento completo da fístula. O grande defeito esofágico resultante da excisão do tumor havia sido coberto com uma aba de pleura parietal invertida retirada no sentido crânio-caudal (Figura $2 \mathrm{AB}$ ).

Os achados histológicos, incluindo imunohistoquímica, foram consistentes com linfoma nãoHodgkin do esôfago do tipo B (Figura 2 C). Três meses após a recuperação da cirurgia, foi instituído um curso completo de quimioterapia, composto por seis ciclos a cada três semanas, com rituximab (anticorpo monoclonal anti CD 20), $375 \mathrm{mg} / \mathrm{m}^{2} \mathrm{IV}$, ciclofosfamida $750 \mathrm{mg} / \mathrm{m}^{2}$, doxorrubicina $50 \mathrm{mg} / \mathrm{m}^{2}$, vincristina $1,4 \mathrm{mg} / \mathrm{m}^{2}$ e $100 \mathrm{mg}$ de prednisona por dia durante cinco dias. Um ano mais tarde, um PET CT foi considerado normal.

\section{COMENTÁRIOS}

O linfoma primário do esôfago não tem etiologia identificável. No entanto, ambos as infecções pelos vírus HIV e Epstein-Barr têm sido relatadas como fatores de risco para o desenvolvimento do linfoma esofágico ${ }^{2}$. Para classificar um linfoma gastrointestinal primário, os seguintes critérios foram propostos por Dawson ${ }^{3}: 1$ - linfonodos superficiais não palpáveis; 2 - radiografia de tórax normal, sem evidência de linfadenomegalia; 3 - contagem de leucócitos normal; 4 -lesão predominante no trato gastrointestinal, com comprometimento de linfonodos confinado à cadeia linfonodal pertencente à drenagem para esse segmento gastrointestinal específico; 5 - ausência de acometimento de fígado e baço.

Em geral, os linfomas do trato gastrointestinal são bastante comuns e compreendem aproximadamente $10 \%$ de todos os linfomas. O esôfago é o local menos comum de linfomas do trato gastrointestinal, representando menos de $1 \%$, enquanto o estômago é afetado em 48$50 \%$ das vezes, o intestino delgado $30-37 \%$ e a área ileocecal, $12-13 \%$. Não há predileção por sexo e, quanto à idade, pode ocorrer entre os 17 a 86 anos $^{4}$. Em pacientes com HIVIAIDS e sintomas como odinofagia, disfagia, perda de peso, dor torácica, febre e fadiga, o linfoma de esôfago deve ser considerado no diagnóstico diferencial, sobretudo nos casos que não respondem à terapia convencional. O risco relativo de pacientes infectados com HIV para o desenvolvimento de linfoma de esôfago é 104 vezes maior quando comparado com pessoas não infectadas com este virus 5 .

O diagnóstico é, por vezes, muito difícil, mesmo com repetidas biópsias esofágicas. A esofagografia com bário pode evidenciar pregas polipóides, ulceradas ou es-

Apresentado, em parte, no segundo Encontro Anual de Terapias Endoscópicas para Distúrbios de Vias Aéreas e do Esôfago, Northwestern University Feinberg School of Medicine, Chicago, Illinois, 12 e 13 de Setembro de 2008.

1. Cirurgião Torácico do Hospital Santa Lúcia, Brasília, DF, Brasil; 2. Hematologista do Centro do Câncer de Brasília - DF-BR. 

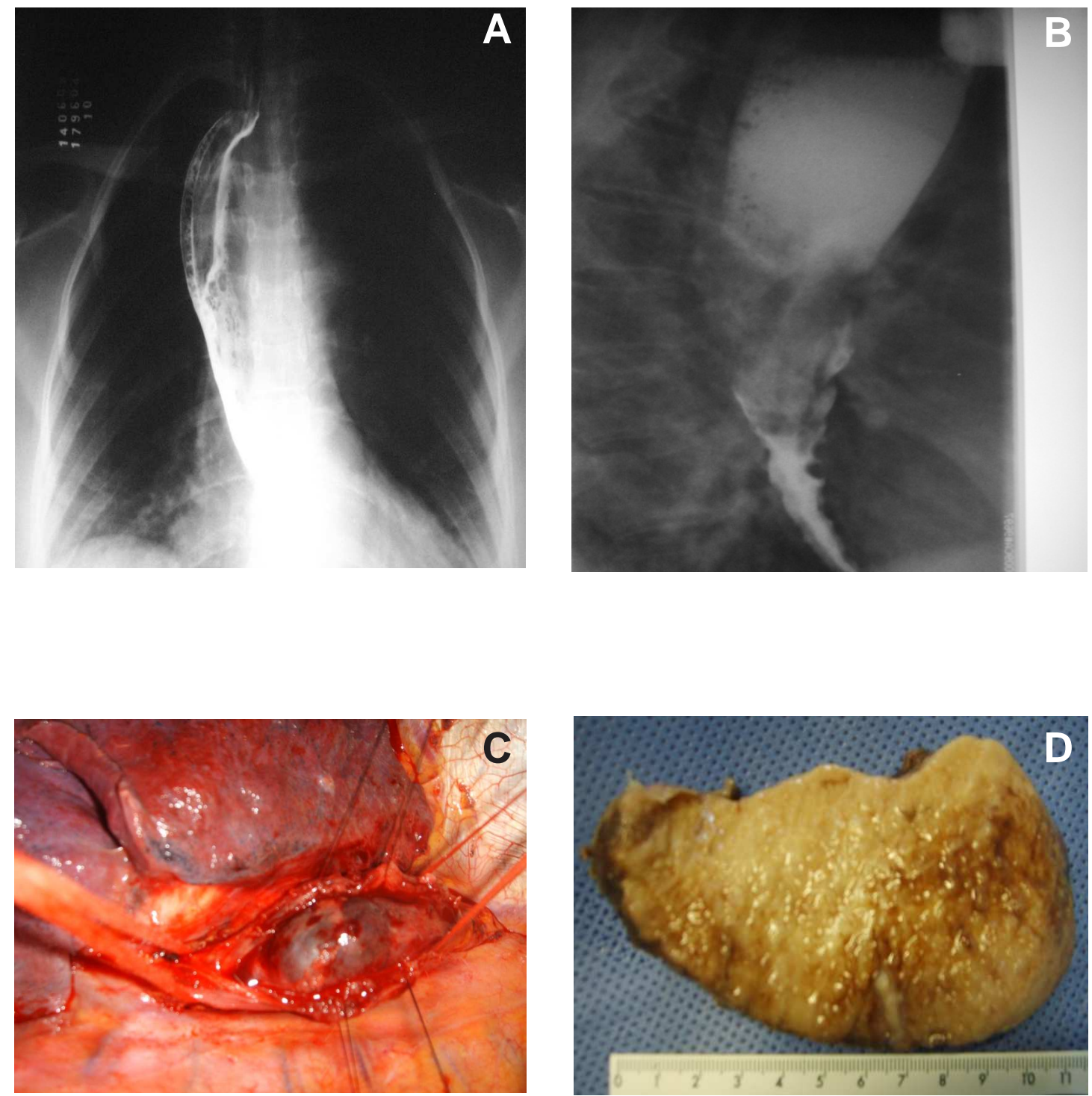

Figura 1 - A e B: esofagografia mostrando uma grande massa esofágica; C: tumor sendo removido; e a peça cirúrgica (D).

pessadas, ou características estenóticas. No nosso caso, o diagnóstico inicial foi de um tumor benigno polipóide que sangrava facilmente.

Os achados histológicos na maioria dos casos de linfoma primário de esôfago são positivos para células B à imunofluorescência, o de grandes células sendo o subtipo mais comumente encontrado. Na avaliação inicial, um exame de sangue completo, biópsia da medula óssea e PET-CT são essenciais para delinear o tratamento a ser realizado. O regime de quimioterapia compreende uma combinação de ciclofosfamida, doxorubicina, vincristina, prednisona e também de rituximab, um anticorpo monoclonal quimérico antiCD20 ig de G1, que resultou em melhores taxas de sobrevida. A radioterapia também tem sido utilizada como uma terapia isolada, mas na maioria dos casos também é usada em conjunto com outras opções, tais como quimioterapia e cirurgia. A cirurgia como única modalidade de tratamento raramente deve ser recomendada. No nosso caso, após a remoção do tumor, foi utilizada, para substituir o defeito esofágico, uma aba reversa pleural em vez de se completar uma esofagectomia, substituindo o órgão com o estômago ou um segmento de cólon. A fístula esôfago-pleural que se desenvolveu foi manejada pelo método descrito por G. Hauer Santos, que consiste em dar grandes quantidades de líquidos claros por via oral assim que o trato fistuloso estiver bem orientado ${ }^{6}$. 

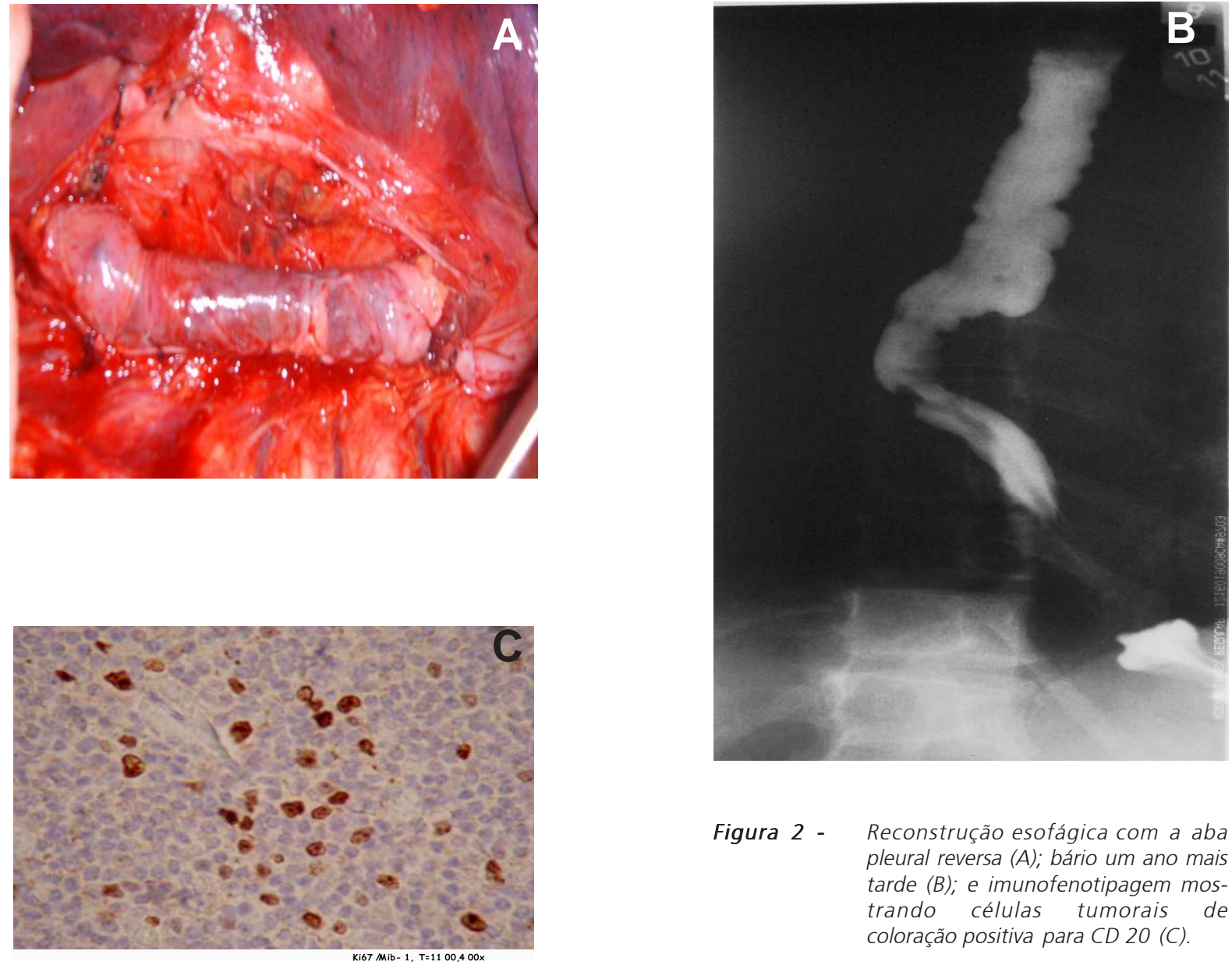

Figura 2 - $\quad$ Reconstrução esofágica com a aba pleural reversa $(A)$; bário um ano mais tarde (B); e imunofenotipagem mostrando células tumorais de coloração positiva para CD 20 (C).

O prognóstico dos linfomas não-Hodgkin, de acordo com o International Lymphoma Prognostic Factors Project, aponta que pacientes acima de 60 anos de idade, estágio do tumor III-IV (classificação de Ann Arbor), performance status 2-4, lactato desidrogenase (LDH) alta no soro e envolvimento extranodal em mais de um local são pacientes de alto risco e a sobrevivência varia entre $73 \%$ a $26 \%$, dependendo da fase. A literatura brasileira relata um caso de linfoma nãoHodgkin primário tratado com cirurgia (esofagectomia) e quimioterapia, com sobrevida até 49 meses.

\title{
A B S T R A C T
}

\begin{abstract}
We describe the case of a 54 year old woman seen with an esophageal mass diagnosed as a primary esophageal lymphoma. The main symptom was dysphagia of seven months duration. The treatment consisted in resection of the tumor, and reconstruction of the defect with a reversed pleural flap, followed by a chemotherapy regimen that consisted of five drugs, cyclophosphamid, prednisone, doxorubicin, rituximab and vincristine (R-CHOP). The patient developed an esophageal pleural fistula treated with pleural drainage and irrigation that closed in 45 days. Two and one half years later she is doing well and disease free.
\end{abstract}

Key words: Neoplasms. Esophageal neoplasms. Esofageal fistula. Lymphoma, AIDS-related, Treatment.

\section{REFERENCIAS}

1. Gupta NM, Goenka MK, Jindal A, Behera A, Vaiphei K. Primary lymphoma of the esophagus. J Clin Gastroenterol. 1996;23(3):203-6.
2. Cappell MS, Botros N. Predominantly gastrointestinal symptoms and signs in 11 consecutive AIDS patients with gastrointestinal lymphoma: a multicenter, multiyear study including 763 HIV-seropositive patients. Am J Gastroenterol. 1994;89(4):545-9. 
3. Dawson IM, Cornes JS, Morson BC. Primary malignant lymphoid tumours of the intestinal tract. Report of 37 cases with a study of factors influencing prognosis. Br J Surg. 1961;49:80-9.

4. Chan JK, Banks PM, Cleary ML, Delsol G, De Wolf-Peeters C, Falini $B$, et al. A revised European-Amnerican classification of lymphoid neoplasm proposed by the International Lymphoma Study Group. A summary version. Am J Clin Pathol. 1995;103(5):543-60.

5. Sabljak P, Stojakov D, Bjelovic M, Mihaljevic B, Velickovic D, Ebrahimi $K$, et al. Primary esophageal diffuse large B-cell lymphoma: report of a case. Surg Today. 2008;36(7):547-50.

6. Santos GH, Frater RW. Transesophageal irrigation for the treatment of mediastinitis produced by esophageal rupture. J Thorac Cardiovasc Surg. 1986;91(1):57-62.
Recebido em 01/08/2008

Aceito para publicação em 02/09/2008

Conflito de interesse: nenhum

Fonte de financiamento: nenhum

\section{Como citar este artigo:}

Ximenes M, Piauilino MA, Oliveira HA, Pinto Neto JV. Primary esophageal lymphoma. Rev Col Bras Cir. [periódico na Internet] 2012; 39(2). Disponível em URL: http://www.scielo.br/rcbc

\section{Endereço para correspondência:}

Manoel Ximenes

E-mail: mximenes@solar.com.br 